\title{
CÁC YÊU TỐ ẢNH HƯởNG ĐẾN CẦU NHậP KHẨU THỦY SẢN CỦA NHẬT BẢN TỪ TH!̣ TRƯỜNG VIẸT NAM
}

\section{CÁC YẾU TỐ ẢNH HƯỞNG ĐẾN CẦU NHẬP KHẨU THỦY SẢN CỦA NHẬT BẢN TƯ THI TRƯỜNG VIẸT NAM}

\author{
Mai Thị Cẩm Tú \\ Trưòng Đại học Kinh tế - Luật - ĐHQG TP.HCM - tumtc@uel.edu.vn \\ (Bài nhận ngày 27 tháng 10 năm 2014, hoàn chỉnh sửa chữa ngày 08 tháng 12 năm 2014)
}

\section{TÓM TÄT}

Nhật Bản là quốc gia nhập khẩu thủy sản hàng đầu thế giới trong suốt những năm 1980 đến năm 2012. Năm 2013, Nhật Bản là thị truờng nhập khẩu thủy sản đứng thư hai trên thế giới (sau Mỹ) với giá trị nhập khẩu là 15,3 tỷ USD, chiếm gần 12\% tổng giá trị nhập khẩu của thế giới. Nhật Bản luôn được xem là thị truờng quan trọng của các nuớc xuất khẩu thủy sản trên thế giới, đặc biệt là các nuớc Châu Á (trong đó có Việt Nam). Việc tìm hiểu và đánh giá mức độ tác động của các yếu tố ảnh huởng đến luợng cầu nhập khẩu thủy sản của Nhật Bản tù Việt Nam có ý nghĩa quan trọg, giúp cho Việt Nam dụ báo được xu huoóng nhập khẩu thủy sản của Nhật Bản trong thời gian tới, tù đó Việt Nam sẽ chủ động nguồn cung xuất khẩu để đáp ưng tốt nhu cầu nhập khẩu thủy sản của Nhật Bản và đồng thời mang về nguồn ngoại tệ cho quốc gia. Tác giả giới hạn ở hai nhóm mặt hàng đó là cá và tôm. Bằng số liệu thư cấp tù năm 1988 - 2013, tác giả sủ dụng phuơng pháp phân tích đồng liên kết của Engle Granger để đo luờng các mối quan hệ dài hạn giữa các biến và mô hình điều chỉnh sai số ECM (Error Correction Model) để đo luờng mối quan hệ ngắn hạn giũa các biến. Kết quả nghiên cứu cho thấy các yếu tố ảnh hưởng đến luợng cầu nhập khẩu thủy sản của Nhật Bản tù̀ thị truờng Việt Nam có sư khác nhau giữa mặt hàng cá và tôm. Các yếu tố ảnh hưởng đến cầu nhập khẩu mặt hàng cá đó là: khối luợng đánh bắt cá của Nhật Bản; tỷ lệ giá nhập khẩu cá của Nhật Bản tù Việt Nam chia cho giá nhập khẩu cá bình quân tù các đối thủ cạnh tranh của Việt Nam trên thị truờng Nhật Bản; tỷ giá hối đoái thực giữa JPY/VND. Các yếu tố ảnh hương đến cầu nhập khẩu mặt hàng tôm đó là: khối luợng nuôi tôm của Nhật Bản; tỷ giá hối đoái thục giũa JPY/VND; hiệp định đối tác thuơng mại Việt Nam-Nhật Bản.

Tù khóa: xuất khẩu, thủy sản, cầu nhập khẩu.

\begin{abstract}
ABTRACT
Japan was the largest aquaculture importer during the period of 1980-2012 and the second largest in 2013 (after the United States) with an import volume of 15.3 billion USD, accounting for about 12\% total world's import volume. Japan has always been an important market to aquaculture exporters, especially Asian countries including Vietnam. The research and evaluation of factors affecting Japan's import demand for Vietnamese aquaculture is of importance. This helps to forecast the import demand for Vietnamese aquaculture of Japan, thereby enhancing the activeness of Vietnam in the provision of aquaculture source of supply to better meet Japan's demand and increasing the foreign currency flow. This research is confined in two products, namely shrimp and fish. Using secondary data from 1988 to
\end{abstract}


2013, the author utilized Engle - Granger cointegration approach to measure the long-term relationship and error correction model (ECM) to measure the short-term relationship between variables. Results indicate that factors affecting Japan's aquaculture demand for Vietnamese shrimp and fish are different. In particular, factors determining the import demand for fish are fishing volume of Japan, the ratio of Vietnamese fish's export price to Japan to that of Vietnam's competitors and the real JPY/VND exchange rate. On the other hand, factors influencing the import demand for shrimp are Japan's shrimp production volume, the real JPY/VND exchange rate and the Vietnam - Japan Economic Partnership Agreement.

Key words: export, aquaculture, import demand.

\section{Giới thiệu}

Nhật Bản là một trong những quốc gia xuất nhập khẩu thủy sản lớn của thế giới và là một trong những thị trường xuất khẩu thủy sản quan trọng của Việt Nam. Năm 2013, giá trị nhập khẩu thủy sản của Nhật Bản từ Việt Nam là $89.479,76$ triệu Yên, tăng $23 \%$ so với năm 2012 về giá trị nhập khẩu. Tuy nhiên, thị phần về các mặt hàng thủy sản của Việt Nam trên thị trường Nhật Bản còn khá khiêm tốn. Năm 2013, thị phần về các mặt hàng thủy sản nói chung của Việt Nam trên thị trường Nhật Bản chiếm tỷ lệ khoảng $6,1 \%$; đối với các mặt hàng cá chiếm khoảng $10 \%$, và các mặt hàng tôm chiếm khoảng $21 \%$.

Mục tiêu của tác giả là đo lường mức độ tác động của các yếu tố ảnh hưởng đến nhu cầu nhập khẩu thủy sản của Nhật Bản từ thị trường Việt Nam. Tác giả giới hạn ở hai nhóm mặt hàng, đó là: mặt hàng cá và mặt hàng tôm.

\section{Cơ sở lý thuyết}

Quốc gia $\mathrm{A}$ sẽ nhập khẩu hàng hóa khi nhu cầu hàng hóa đó trong nước lớn hơn nguồn cung trong nước. Khối lượng nhập khẩu hàng hóa của quốc gia $\mathrm{A}$ phụ thuộc vào sự biến động giữa lượng cung và lượng cầu trong nước tại các mức giá hàng hóa đó trên thị trường thế giới. $Q_{d}^{W}$ là tổng cầu nhập khẩu hàng hóa của quốc gia $\mathrm{A}$ từ thế giới. $Q_{x}^{r}$ là lượng cầu nhập khẩu hàng hóa từ các quốc gia khác (trừ quốc gia $\mathrm{B}$ ) của quốc gia $\mathrm{A}$. Lượng cầu nhập khẩu hàng hóa của quốc gia $\mathrm{A}$ từ quốc gia $\mathrm{B}$
$Q_{d}^{w}-Q_{x}^{r}, \varepsilon_{d}^{w}$ là độ co giãn của cầu nhập khẩu theo giá của quốc gia $\mathrm{A}$ từ thị trường thế giới. $\varepsilon_{d}^{x}$ là độ co giãn của cầu nhập khẩu theo giá của quốc gia $\mathrm{A}$ từ quốc gia $\mathrm{B}$. $\varepsilon_{s}^{r}$ độ co giãn của cầu nhập khẩu theo giá của quốc gia $\mathrm{A}$ từ các quốc gia khác (trừ quốc gia $\mathrm{B}$ ). Độ co giãn của cầu nhập khẩu theo giá của quốc gia $\mathrm{A}$ từ quốc gia $\mathrm{B}$ được biểu diễn như sau:

$\varepsilon_{d}^{x}=\frac{Q_{d}^{w}}{Q_{d}^{w}-Q_{x}^{r}} \times \varepsilon_{d}^{w}+\frac{Q_{x}^{r}}{Q_{d}^{w}-Q_{x}^{r}} \times \varepsilon_{s}^{r}$

Như vậy, độ co giãn của cầu nhập khẩu theo giá của quốc gia $\mathrm{A}$ từ quốc gia $\mathrm{B}$ quan hệ tỷ lệ nghịch với khối lượng nhập khẩu hàng hóa của quốc gia $\mathrm{A}$ từ quốc gia $\mathrm{B}$ và quan hệ tỷ lệ thuận với độ co giãn của cầu nhập khẩu theo giá của quốc gia $\mathrm{A}$ từ thị trường thế giới và độ co giãn của cầu nhập khẩu theo giá của quốc gia $\mathrm{A}$ từ các nước khác (trừ quốc gia $\mathrm{B}$ ). Mô hình (1) khó ước lượng được vì khó biết được $\boldsymbol{\varepsilon}_{d}^{x}$ và $\varepsilon_{s}^{r}$. Bằng các công trình nghiên cứu thực nghiệm của Khan (1978, 1985), Bond (1985), Gunawardana and Karn $(1998,2002)$ về cầu nhập khẩu hàng hóa của quốc gia $\mathrm{A}$ từ quốc gia $\mathrm{B}$, lượng cầu nhập khẩu hàng hóa của quốc gia $\mathrm{A}$ từ quốc gia $\mathrm{B}$ được biểu diễn lại như sau:

$\ln X_{t}^{d}=\beta_{0}+\beta_{1} \ln (P X / P X W)_{t}+\beta_{2} \ln Y W_{t}$

$\ln X_{t}^{d}$ : Lượng cầu nhập khẩu hàng hóa của quốc gia $\mathrm{A}$ từ quốc gia $\mathrm{B} ; \mathrm{PX}$ : Giá hàng hóa nhập khẩu của quốc gia $\mathrm{A}$ từ quốc gia $\mathrm{B} ; \mathrm{PXW}$ : giá hàng hóa nhập khẩu bình quân của quốc gia 
$\mathrm{A}$ từ các nước trên thế giới (trừ quốc gia $\mathrm{B}$ ); YW: mức thu nhập của nước nhập khẩu A. Dấu kỳ vọng $\beta_{1}<0, \beta_{2}>0$. Lượng cầu nhập khẩu của quốc gia $\mathrm{A}$ từ quốc gia $\mathrm{B}$ có quan hệ tỷ lệ nghịch với tỷ lệ giữa giá nhập khẩu từ quốc gia $\mathrm{B}$ và giá nhập khẩu bình quân từ các quốc gia khác (trừ quốc gia $\mathrm{B}$ ); quan hệ tỷ lệ thuận với mức thu nhập của quốc gia $\mathrm{A}$.

\section{Dữ liệu và phương pháp nghiên cứu}

Nghiên cứu sử dụng số liệu thứ cấp theo năm từ 1988 - 2013. Dữ liệu nghiên cứu được thu thập từ Cục Hải quan Nhật Bản, Niêm giám thống kê Việt Nam, Ngân hàng thế giới, Bộ Nông nghiệp, Lâm nghiệp và Thủy sản Nhật Bản, Ngân hàng thế giới.

Để đo lường tác động của các yếu tố ảnh hưởng đến nhu cầu nhập khẩu thủy của Nhật Bản từ thị trường Việt Nam, trên cơ sở kế thừa các yếu tố ở mô hình (2) đó là: mức thu nhập của nước nhập khẩu và tỷ lệ giá nhập khẩu, tác giả giả định có 3 yếu tố mới có ảnh hưởng đến cầu nhập khẩu đó là: khối lượng sản xuất thủy sản của Nhật Bản; tỷ giá hối đoái thực JPY/VNĐ và hiệp định đối tác thương mại Việt Nam - Nhật Bản (VJEPA).

Mô hình nghiên cứu và các giả thuyết nghiên cứu như sau.

Biến phụ thuộc. Khối lượng thủy sản nhập khẩu của Nhật Bản từ Việt Nam. Ký hiệu QVJ.
Các biến độc lập và các giả thuyết nghiên cứu.

+ Giả thuyết 1: Tỷ lệ giữa giá nhập khẩu thủy sản của Nhật Bản từ Việt Nam chia cho giá nhập khẩu thủy sản bình quân từ các đối thủ cạnh tranh của Việt Nam trên thị trường Nhật Bản (sau đây gọi tắt là tỷ lệ giá nhập khẩu). Tỷ lệ giá nhập khẩu tác động âm lên cầu nhập khẩu thủy sản của Nhật Bản từ Việt Nam. Ký hiệu là $\mathrm{P}$.

+ Giả thuyết 2: Mức thu nhập bình quân đầu người của người Nhật Bản tác động dương lên cầu nhập khẩu thủy sản của Nhật Bản từ Việt Nam. Ký hiệu là INCJ.

+ Giả thuyết 3: Tỷ giá hối đoái thực JPY/VNĐ tác động dương lên cầu nhập khẩu thủy sản của Nhật Bản từ Việt Nam. Ký hiệu là REX.

+ Giả thuyết 4: Khối lượng sản xuất thủy sản của Nhật Bản tác động âm cầu nhập khẩu thủy sản của Nhật Bản từ Việt Nam. Ký hiệu là QJ.

+ Giải thuyết 5: Hiệp định đối tác kinh tế Việt Nam - Nhật Bản (VJEPA) có thể tác động âm hoặc có thể tác động dương lên cầu nhập khẩu thủy sản của Nhật Bản từ Việt Nam. Ký hiệu là VJEPA.

Mô hình nghiên cứu được biểu diễn dưới dạng công thức sau:

$$
\ln Q V J_{t}=\beta_{0}+\beta_{1} \ln P_{t}+\beta_{2} \operatorname{lnINCJ}_{t}+\beta_{3} \ln R E X_{t}+\beta_{4} \ln Q J_{t}+\beta_{5} V J E P A+\varepsilon_{t} \text { (3) }
$$

$Q V J_{t}$ : là khối lượng thủy sản nhập khẩu của Nhật Bản từ thị trường Việt Nam thời điểm $\mathrm{t}$; (tấn)

$P_{t}$ : là tỷ lệ giữa giá nhập khẩu thủy sản từ Việt Nam chia cho giá bình quân của các đối thủ cạnh tranh của Việt Nam trên thị trường Nhật Bản tại thời điểm $\mathrm{t}$;

$I N C J_{t}$ : mức thu nhập bình quân đầu người của Nhật Bản tại thời điểm t; (USD)
$R E X_{t}$ : tỷ giá hối đoái thực giữa JPY/VNĐ tại thời điểm $\mathrm{t}$;

$Q J_{t}$ : khối lượng sản xuất thủy sản của Nhật Bản tại thời điểm $\mathrm{t}$; (tấn)

VJEPA : hiệp định đối tác kinh tế Việt Nam Nhật Bản; VJEPA là biến giả nhận giá trị 0 từ năm 1988 đến 2008, và nhận giá trị 1 từ 2009 đến năm 2013 
$\varepsilon_{t}$ : phần nhiễu trắng.

Dấu kỳ vọng: $\beta_{1}, \beta_{4}<0 ; \beta_{2}, \beta_{3}>0 ; \beta_{5}><0$.

Mô hình (3) này được dùng để đo lường tác động của các yếu tố ảnh hưởng đến nhu cầu nhập khẩu mặt hàng cá và tôm của Nhật Bản từ thị trường Việt Nam.

Phương pháp được sử dụng là nghiên cứu định lượng. Bước 1, tác giả kiểm định tính dừng của chuỗi dữ liệu bằng phương pháp kiểm định ADF (Augmented Dickey - Fuller); xác định bậc tích hợp giữa các biến; Bước 2 , kiểm định đồng tích hợp (Cointegrated Test) bằng phương pháp Johansen Cointegrated Test để xem xét có tồn tại mối tương quan trong dài hạn giữa các biến đang nghiên cứu; đo lường mối quan hệ dài hạn giữa các biến và mô hình điều chỉnh sai số ECM (Error Correction Model) để đo lường mối quan hệ ngắn hạn giữa các biến.

\section{Kết quả nghiên cứu}

\subsection{Kiểm định tính dừng và bậc tích} họpp

Bảng 1a: Kết quả kiểm định tính dừng và bậc tích hợp của các biến (đối với mặt hàng cá)

\begin{tabular}{|c|c|c|c|c|}
\hline Biến & $\begin{array}{c}\text { ADF test statistic } \\
\text { at level }\end{array}$ & $\begin{array}{c}\text { ADF test statistic } \\
\text { at } \\
\text { first difference }\end{array}$ & Bậc tích họ̣p & Ghi chú \\
\hline LQVJ & -0.558813 & $-5.161016 * * *$ & $\mathrm{I}(1)$ & \multirow{5}{*}{$\begin{array}{l}* * *, * *, * \text { có ý ý } \\
\text { nghĩa thống kê ở } \\
\text { mức } 1 \%, 5 \% \text { và } \\
10 \% \text {. }\end{array}$} \\
\hline LQJ & $-3.834199 * *$ & $-5.590970 * * *$ & $\mathrm{I}(0)$ & \\
\hline LREX & $-3.567901 * *$ & $-3.578413 * *$ & $\mathrm{I}(0)$ & \\
\hline LINCJ & -3.232049 & $-3.410299 *$ & $\mathrm{I}(1)$ & \\
\hline LP & $-3.663714 * *$ & $-7.341071 * * *$ & $\mathrm{I}(0)$ & \\
\hline
\end{tabular}

Nguồn: tác giả tính toán tù Eview 7.0

Từ kết quả bảng 1a, chuỗi dữ liệu ban đầu (ở mức level) chỉ có biến LQJ, LREX và $L P$ dừng ở mức ý nghĩa $5 \%$, các biến còn lại không dừng. Ở mức sai phân bậc 1 (first difference) tất cả các biến đều dừng.

Bảng 1b: Kết quả kiểm định tính dừng và bậc tích hợp của các biến (đối với mặt hàng tôm)

\begin{tabular}{|c|c|c|c|c|}
\hline Biến & $\begin{array}{l}\text { ADF test statistic } \\
\text { at level }\end{array}$ & $\begin{array}{c}\text { ADF test statistic } \\
\text { at } \\
\text { first difference }\end{array}$ & Bậc tích hợp & Ghi chú \\
\hline LQVJ & -1.624456 & $-6.613558 * * *$ & $\mathrm{I}(1)$ & \multirow{5}{*}{$\begin{array}{l}* * *, * *, * \text { có ý } \\
\text { nghĩa thống kê } \\
\text { ở mức } 1 \%, 5 \% \\
\text { và } 10 \% \text {. }\end{array}$} \\
\hline LQJ & -2.327672 & $-4.241779 * *$ & $\mathrm{I}(1)$ & \\
\hline LREX & $-3.567901 * *$ & $-3.578413 * *$ & $\mathrm{I}(0)$ & \\
\hline LINCJ & -3.232049 & $-3.410299 *$ & $\mathrm{I}(1)$ & \\
\hline LP & -0.965650 & $-5.104773 * *$ & $\mathrm{I}(1)$ & \\
\hline
\end{tabular}

Nguồn: tác giả tính toán tù Eview 7.0

Từ kết quả bảng $1 \mathrm{~b}$, chuỗi dữ liệu ban đầu (ở mức level) chỉ có biến LREX dừng ở mức ý nghĩa 5\%. Ở mức sai phân bậc 1 (first difference), tất cả các biến đều dừng. 


\subsection{Kiểm định đồng tích hợp}

\begin{tabular}{|c|c|c|c|c|}
\hline \multicolumn{5}{|c|}{$\begin{array}{l}\text { Bảng 2a: Kết quả kiểm định đồng liên kết } \\
\text { Johansen Cointegration Test (đối với mặt hàng cá) } \\
\text { Unrestricted Cointegration Rank Test (Trace) }\end{array}$} \\
\hline \multirow{2}{*}{\multicolumn{2}{|c|}{ Hypothesized }} & Trace & 0.05 & \\
\hline & & & Critical & \\
\hline No. of CE(s) & Eigenvalue & Statistic & Value & Prob.** \\
\hline None * & 0.954520 & 174.6207 & 95.75366 & 0.0000 \\
\hline At most $1 *$ & 0.858180 & 100.4491 & 69.81889 & 0.0000 \\
\hline At most $2 *$ & 0.685408 & 53.57228 & 47.85613 & 0.0132 \\
\hline At most 3 & 0.551807 & 25.81681 & 29.79707 & 0.1343 \\
\hline At most 4 & 0.198421 & 6.556075 & 15.49471 & 0.6298 \\
\hline At most 5 & 0.050669 & 1.247940 & 3.841466 & 0.2639 \\
\hline
\end{tabular}

Trace test indicates 3 cointegrating eqn(s) at the 0.05 level

* denotes rejection of the hypothesis at the 0.05 level

**MacKinnon - Haug - Michelis (1999) p-values

Unrestricted Cointegration Rank Test (Maximum Eigenvalue)

\begin{tabular}{ccccc}
\hline \hline Hypothesized & & Max-Eigen & 0.05 & \\
& & & Critical & \\
No. of CE(s) & Eigenvalue & Statistic & Value & Prob.** \\
\hline \hline None * & 0.954520 & 74.17160 & 40.07757 & 0.0000 \\
At most 1 $*$ & 0.858180 & 46.87679 & 33.87687 & 0.0008 \\
At most 2* & 0.685408 & 27.75547 & 27.58434 & 0.0475 \\
At most 3 & 0.551807 & 19.26073 & 21.13162 & 0.0895 \\
At most 4 & 0.198421 & 5.308135 & 14.26460 & 0.7025 \\
At most 5 & 0.050669 & 1.247940 & 3.841466 & 0.2639 \\
& & & & \\
\hline
\end{tabular}

Max-eigenvalue test indicates 3 cointegrating eqn(s) at the 0.05 level

* denotes rejection of the hypothesis at the 0.05 level

**MacKinnon-Haug-Michelis (1999) p-values

Bảng 2b: Kêt quả kiêm định đông liên kêt

Johansen Cointegration Test (đối với mặt hàng tôm)

Unrestricted Cointegration Rank Test (Trace)

\begin{tabular}{ccccc}
\hline \hline Hypothesized & & Trace & 0.05 \\
& & & Critical & \\
No. of CE(s) & Eigenvalue & Statistic & Value & Prob.** \\
\hline \hline None * & 0.880810 & 147.7366 & 95.75366 & 0.0000 \\
At most 1 * & 0.834900 & 96.68773 & 69.81889 & 0.0001 \\
At most 2* & 0.685010 & 53.45880 & 47.85613 & 0.0136 \\
At most 3 & 0.546718 & 25.73363 & 29.79707 & 0.1369 \\
At most 4 & 0.240580 & 6.743864 & 15.49471 & 0.6076 \\
At most 5 & 0.005778 & 0.139065 & 3.841466 & 0.7092 \\
\hline
\end{tabular}

Trace test indicates 3 cointegrating eqn(s) at the 0.05 level

$*$ denotes rejection of the hypothesis at the 0.05 level

**MacKinnon - Haug - Michelis (1999) p-values

Unrestricted Cointegration Rank Test (Maximum Eigenvalue)

\begin{tabular}{ccccc}
\hline \hline Hypothesized & & Max-Eigen & 0.05 \\
Critical & \\
No. of CE(s) & Eigenvalue & Statistic & Value & Prob.** \\
\hline \hline None * & 0.880810 & 51.04884 & 40.07757 & 0.0020 \\
At most 1 * & 0.834900 & 43.22893 & 33.87687 & 0.0029 \\
At most 2* & 0.685010 & 27.72517 & 27.58434 & 0.0480 \\
At most 3 & 0.546718 & 18.98976 & 21.13162 & 0.0971 \\
At most 4 & 0.240580 & 6.604799 & 14.26460 & 0.5369 \\
At most 5 & 0.005778 & 0.139065 & 3.841466 & 0.7092 \\
& & & & \\
\hline \hline
\end{tabular}

Max-eigenvalue test indicates 3 cointegrating eqn(s) at the 0.05 level

* denotes rejection of the hypothesis at the 0.05 level

**MacKinnon-Haug-Michelis (1999) p-values 
Từ kết quả trong bảng $2 \mathrm{a}$ và $2 \mathrm{~b}$, cả hai kiểm định mà Johansen và Juselius (1990) đưa ra là kiểm định vết ma trận (trace) và kiểm định giá trị riêng cực đại của ma trận (Max-Eigenvalue) đều khẳng định tồn tại ít nhất ba vectơ đồng tích hợp ở mức ý nghĩa $5 \%$. Điều này chứng minh rằng có mối quan hệ dài hạn mạnh (đồng tích hợp) giữa các biến nghiên cứu.

\subsection{Mô hình hồi quy đồng tích hợp}

\subsection{1. Đối với mặt hàng cá}

Từ kết quả hồi quy ban đầu theo mô hình (3), tác giả lần lượt loại bỏ các biến không có ý nghĩa thống kê và mô hình hồi quy đồng tích hợp tối ưu và các kiểm định chuẩn đoán mô hình như sau:

Bảng 3a: Kết quả ước lượng mô hình hồi quy tích hợp (đối với mặt hàng cá)

Dependent Variable: LQVJ

\begin{tabular}{|c|c|c|c|c|c|}
\hline Variable & Coefficient & \multicolumn{2}{|c|}{ Std. Error } & t-Statistic & Prob. \\
\hline LQJ & -4.507472 & \multicolumn{2}{|c|}{1.931374} & -2.333817 & 0.0291 \\
\hline LP & -4.233298 & \multicolumn{2}{|c|}{0.978015} & -4.328460 & 0.0003 \\
\hline LREX & 0.808223 & \multicolumn{2}{|c|}{0.288280} & 2.803604 & 0.0104 \\
\hline $\mathrm{C}$ & 70.22145 & \multicolumn{2}{|c|}{27.06896} & 2.594169 & 0.0166 \\
\hline \multicolumn{3}{|c|}{ Các kết quả kiểm định chuẩn đoán mô hình } & & & \\
\hline \multicolumn{2}{|c|}{ Kiểm định phân phối chuẩn } & \multicolumn{3}{|c|}{ Jarque-Bera $=1.634200$} & Prob $=0.441711$ \\
\hline \multicolumn{3}{|c|}{ Kiểm định tự tương quan Breush - Godfrey LM } & \multicolumn{2}{|c|}{ Chi square $=0.966820$} & Prob $=0.3452$ \\
\hline \multicolumn{3}{|c|}{ Kiểm định phương sai thay đổi - Heteroskedasticity } & Chi sc & $=0.7635$ & Prob $=0.346$ \\
\hline
\end{tabular}

Nguồn: tác giả tính toán tù Eview 7.0

R-squared $=0.666557$, cho biết mô hình giải thích được 66,65\% sự phụ thuộc của khối lượng nhập khẩu cá của Nhật Bản từ Việt Nam vào các yếu tố như: khối lượng đánh bắt cá của Nhật Bản; tỷ lệ giữa giá nhập khẩu từ Việt Nam và giá nhập khẩu từ các đối thủ cạnh tranh và tỷ giá hối đoái thực giữa Nhật Bản và Việt Nam.

Trước hết, biến LQJ = -4.507472, có ý nghĩa thống kê ở mức dưới $5 \%$, phù hợp với giả thuyết 4 , cho thấy khối lượng đánh bắt cá của Nhật Bản tăng sẽ làm lượng cung cá trong nước tăng và cầu nhập khẩu cá giảm và ngược lại. Với các yếu tố khác không đổi, khối lượng đánh bắt cá của Nhật Bản tăng một tấn thì khối lượng nhập khẩu cá của Nhật Bản từ Việt Nam giảm đi 4,507472 tấn.

Kế tiếp, biến LP $=-4.233298$, có ý nghĩa thống kê ở mức $0 \%$, phù hợp với giả thuyết 1 , cho thấy tỷ lệ giữa giá nhập khẩu cá từ Việt Nam chia cho giá nhập khẩu của các đối thủ Việt Nam trên thị trường Nhật Bản tăng (nghĩa là giá nhập khẩu cá của Việt Nam cao hơn giá nhập khẩu của các đối thủ cạnh tranh) thì khối lượng nhập khẩu cá của Nhật Bản từ Việt Nam giảm và ngược lại. Với các yếu tố khác không 
đổi, tỷ lệ giữa giá nhập khẩu cá từ Việt Nam chia cho giá nhập khẩu từ các đối thủ của Việt Nam trên thị trường Nhật Bản tăng một lần thì khối lượng nhập khẩu cá của Nhật Bản từ Việt Nam giảm 4,233298 tấn.

Cuối cùng, biến LREX $=0.808223$, có ý nghĩa thống kê ở mức $1 \%$, phù hợp với giả thuyết 3 , cho thấy tỷ giá hối đoái thực giữa JPY/VNĐ tăng thì khối lượng nhập khẩu cá của Nhật Bản từ Việt Nam tăng và ngược lại. Với các yếu tố khác không đổi, tỷ giá hối đoái thực giữa JPY/VNĐ tăng một đồng thì khối lượng nhập khẩu cá của Nhật Bản từ Việt Nam tăng 0,808223 tấn.
Như vậy, trong dài hạn, các yếu tố ảnh hưởng đến khối lượng nhập khẩu cá của Nhật Bản từ Việt Nam đó là: khối lượng đánh bắt cá của Nhật Bản; tỷ lệ giữa giá nhập khẩu cá từ Việt Nam chia cho giá nhập khẩu của các đối thủ Việt Nam trên thị trường Nhật Bản.

\subsection{2. Đối với mặt hàng tôm}

Sau khi loại bỏ các biến không có ý nghĩa thống kê từ kết quả ước lượng mô hình hồi quy đồng tích hợp ban đầu, mô hình hồi quy đồng tích hợp tối ưu và các kiểm định chuẩn đoán mô hình như sau:

Bảng 3b: Kết quả ước lượng mô hình hồi quy tích hợp (đối với mặt hàng tôm)

Dependent Variable: LQVJ

\begin{tabular}{cllll}
\hline \hline Variable & Coefficient & Std. Error & t-Statistic & Prob. \\
\hline \hline LREX & 0.141197 & 0.053108 & 2.658686 & 0.0143 \\
LQJ & -0.905725 & 0.104911 & -8.633292 & 0.0000 \\
VJEPA & -0.352503 & 0.091919 & -3.834917 & 0.0009 \\
C & 19.72028 & 1.271692 & 15.50712 & 0.0000 \\
\hline \hline R-squared & 0.838034 & \multicolumn{2}{c}{ Adjusted R-squared } & 0.815948 \\
\hline \hline
\end{tabular}

Các kết quả kiểm định chuẩn đoán mô hình

\begin{tabular}{|l|l|l|}
\hline Kiểm định phân phối chuẩn & Jarque-Bera $=1.944816$ & Prob $=0.37811$ \\
\hline Kiểm định tự tương quan Breush - Godfrey LM & Chi square $=0.6165$ & Prob $=0.6844$ \\
\hline Kiểm định phương sai thay đổi - Heteroskedasticity & Chi square $=0.4190$ & Prob $=0.4902$ \\
\hline
\end{tabular}

Nguồn: tác giả tính toán tì̀ Eview 7.0 
R-squared $=0.815948$, cho biết mô hình giải thích được $81,15 \%$ sự phụ thuộc của khối lượng nhập khẩu tôm của Nhật Bản từ Việt Nam vào các yếu tố như: khối lượng nuôi tôm của Nhật Bản; hiệp định đối tác kinh tế Việt Nam - Nhật Bản và tỷ giá hối đoái thực giữa Nhật Bản và Việt Nam.

Trước hết, biến LQJ = -0.905725, có ý nghĩa thống kê ở mức $0 \%$, phù hợp với giả thuyết 4 , cho thấy khối lượng nuôi tôm của Nhật Bản tăng sẽ làm lượng cung tôm trong nước tăng và cầu nhập khẩu tôm giảm và ngược lại. Với các yếu tố khác không đổi, khối lượng nuôi tôm của Nhật Bản tăng một tấn thì khối lượng nhập khẩu tôm của Nhật Bản từ Việt Nam giảm đi 0,905725tấn.

Kế tiếp, biến VJEPA $=-0.352503$, có ý nghĩa thống kê ở mức $0 \%$, phù hợp với giả thuyết 5 , cho thấy hiệp định đối tác thương mại Việt Nam - Nhật Bản làm giảm khối lượng nhập khẩu tôm của Nhật Bản từ Việt Nam. Điều này có thể dễ dàng nhận thấy, do những ràng buộc về các quy định an toàn thực phẩm, quy định nhãn mác và quy trình nhập khẩu theo VJEPA quá khắc nghiệt và khó cho các doanh nghiệp Việt Nam trong giai đoạn đầu khi áp dụng VJEPA. Với các yếu tố khác không đổi, khi hiệp định đối tác thương mại Việt Nam Nhật Bản có hiệu lực thì khối lượng nhập khẩu tôm của Nhật Bản từ Việt Nam giảm 0,352503 tấn/năm.

Cuối cùng, biến LREX $=0.141197$, có ý nghĩa thống kê ở mức dưới $5 \%$, phù hợp với giả thuyết 3 , cho thấy tỷ giá hối đoái thực giữa JPY/VNĐ tăng thì khối lượng nhập khẩu tôm của Nhật Bản từ Việt Nam tăng và ngược lại. Với các yếu tố khác không đổi, tỷ giá hối đoái thực giữa JPY/VNĐ tăng một đồng thì khối lượng nhập khẩu tôm của Nhật Bản từ Việt Nam tăng 0,141197 tấn.

Như vậy, trong dài hạn, các yếu tố ảnh hưởng đến khối lượng nhập khẩu tôm của Nhật Bản từ Việt Nam đó là: khối lượng nuôi tôm của Nhật Bản; hiệp định đối tác kinh tế Việt Nam - Nhật Bản và tỷ giá hối đoái thực giữa JPY/VNĐ.

\subsection{Phân tích cân bằng ngắn hạn - Mô hình ECM}

\subsection{1. Đối với mặt hàng cá}

Bảng 4a: Kết quả ước lượng mô hình hiệu chỉnh sai số (đối với mặt hàng cá)

Dependent Variable: DLQVJ

\begin{tabular}{ccccc}
\hline \hline Variable & Coefficient & Std. Error & t-Statistic & Prob. \\
\hline \hline DLREX & -0.034407 & 0.118874 & -0.289439 & 0.7752 \\
DLQJ & $-5.09 \mathrm{E}-07$ & $3.45 \mathrm{E}-07$ & -1.472466 & 0.1565 \\
DLP & -0.694955 & 0.313982 & -2.213358 & 0.0387 \\
ECT(-1) & -0.091768 & 0.046431 & -1.976413 & 0.0621 \\
C & -0.478835 & 0.421376 & -1.136361 & 0.2692 \\
\hline \hline & & & & 0.336373
\end{tabular}

Trang 124 
Các kết quả kiểm định chuẩn đoán mô hình

\begin{tabular}{|l|l|l|}
\hline Kiểm định phân phối chuẩn & Jarque-Bera $=2.8559837$ & Prob $=0.239328$ \\
\hline $\begin{array}{l}\text { Kiểm định tự tương quan Breush }- \\
\text { Godfrey LM }\end{array}$ & Chi square $=0.2457$ & Prob $=0.2376$ \\
\hline $\begin{array}{l}\text { Kiểm định phương sai thay đổi }- \\
\text { Heteroskedasticity }\end{array}$ & Chi square $=0.9333$ & Prob $=0.9914$ \\
\hline
\end{tabular}

Nguồn: tác giả tính toán tù Eview 7.0Trong ngắn hạn, kết quả nghiên cứu cho thấy các hệ số hồi quy có ý nghĩa thống kê ở mức 5\% được chọn là DLP và ECT(-1) có ý nghĩa thống kê ở mức $10 \%$.

DLP: với mức ý nghĩa $5 \%$, biến thiên của tỷ lệ giữa giá nhập khẩu cá của Nhật Bản từ Việt Nam chia cho giá nhập khẩu cá của các đối thủ cạnh tranh của Việt Nam trên thị trường Nhật Bản có quan hệ ngược chiều với biến thiên của khối lượng nhập khẩu cá của Nhật Bản từ Việt Nam. Biến thiên của tỷ lệ giữa giá nhập khẩu cá của Nhật Bản từ Việt Nam chia cho giá nhập khẩu cá của các đối thủ cạnh tranh của Việt Nam trên thị trường Nhật Bản tăng $1 \%$ thì biến thiên khối lượng nhập khẩu cá của Nhật Bản từ Việt Nam giảm $0.69 \%$.

$\mathrm{ECT}(-1)=-0.091768$ : có nghĩa là giá trị biến thiên của khối lượng nhập khẩu cá của Nhật Bản từ Việt Nam bị khử đi khoảng
0,091768; đây cũng là mức chênh lệch giữa biến thiên ngắn hạn và dài hạn. ECT(-1) âm cũng cho thấy sự điều chỉnh khối lượng nhập khẩu cá của Nhật Bản từ Việt Nam là do hệ số này điều chỉnh sai số.

Như vậy, trong ngắn hạn, khối lượng nhập khẩu cá của Nhật Bản từ Việt Nam sẽ bị tác động bởi xu hướng biến động của khối lượng nhập khẩu cá của Nhật Bản từ Việt Nam năm trước đó và tỷ lệ giữa giá nhập khẩu cá của Nhật Bản từ Việt Nam chia cho giá nhập khẩu cá của các đối thủ cạnh tranh của Việt Nam trên thị trường Nhật Bản.

\subsection{2. Đối với mặt hàng tôm}

Bảng 4b: Kết quả ước lượg mô hình hiệu chỉnh sai số (đối với mặt hàng tôm)

\begin{tabular}{lllll}
\hline \hline Variable & Coefficient & Std. Error & t-Statistic & Prob. \\
\hline \hline DLREX & 0.058823 & 0.067413 & 0.872570 & 0.3933 \\
DLQJ & -1.646773 & 0.646329 & -2.547886 & 0.0192 \\
ECT(-1) & -0.669028 & 0.193956 & -3.449374 & 0.0025 \\
VJEPA & -0.082369 & 0.062297 & -1.322201 & 0.2010 \\
C & -0.030089 & 0.042488 & -0.708171 & 0.4870 \\
\hline \hline R-squared & 0.502454 & Adjusted R-squared & 0.402944 \\
\hline \hline
\end{tabular}


Các kết quả kiểm định chuẩn đoán mô hình

\begin{tabular}{|l|l|l|}
\hline Kiểm định phân phối chuẩn & Jarque-Bera $=1.344742$ & Prob $=0.510497$ \\
\hline $\begin{array}{l}\text { Kiểm định tự tương quan Breush - } \\
\text { Godfrey LM }\end{array}$ & Chi square $=0.5645$ & Prob $=0.6561$ \\
\hline $\begin{array}{l}\text { Kiểm định phương sai thay đổi }- \\
\text { Heteroskedasticity }\end{array}$ & Chi square $=0.4837$ & Prob $=0.6131$ \\
\hline
\end{tabular}

Nguồn: tác giả tính toán tì̀ Eview 7.0

Trong ngắn hạn, kết quả nghiên cứu cho thấy các hệ số hồi quy có ý nghĩa thống kê ở mức $5 \%$ được chọn là DLQJ và $\mathrm{ECT}(-1)$ có ý nghĩa thống kê ở mức $1 \%$.

DLQJ: với mức ý nghĩa $5 \%$, biến thiên của khối lượng nuôi tôm của Nhật Bản có quan hệ ngược chiều với biến thiên của khối lượng nhập khẩu tôm của Nhật Bản từ Việt Nam. Biến thiên của khối lượng nuôi tôm của Nhật Bản tăng $1 \%$ thì biến thiên khối lượng nhập khẩu tôm của Nhật Bản từ Việt Nam giảm $1.64 \%$.

ECT $(-1)=-0.669028$ : có nghĩa là giá trị biến thiên của khối lượng nhập khẩu tôm của Nhật Bản từ Việt Nam bị khử đi khoảng 0,669028; đây cũng là mức chênh lệch giữa biến thiên ngắn hạn và dài hạn. ECT(-1) âm cũng cho thấy sự điều chỉnh khối lượng nhập khẩu tôm của Nhật Bản từ Việt Nam là do hệ số này điều chỉnh sai số.

Như vậy, trong ngắn hạn, khối lượng nhập khẩu tôm của Nhật Bản từ Việt Nam sẽ bị tác động bởi xu hướng biến động của khối lượng nhập khẩu tôm của Nhật Bản từ Việt Nam năm trước đó và khối lượng nuôi tôm của Nhật Bản.

\section{Kết luận}

Nhật Bản là một trong ba thị trường xuất khẩu thủy sản chủ lực của Việt Nam. Tìm hiểu các yếu tố ảnh hưởng đến cầu nhập khẩu thủy sản của Nhật Bản từ thị trường Việt Nam là cần thiết, góp phần dự báo được nhu cầu nhập khẩu thủy sản của Nhật Bản trong những năm tới và giúp Việt Nam chủ động được nguồn cung xuất khẩu thủy sản nhằm đáp ứng tốt nhất nhu cầu nhập khẩu thủy sản của Nhật Bản và góp phần phát triển xuất khẩu thủy sản Việt Nam. Bằng phương pháp định lượng với các số liệu thống kê thứ cấp từ năm 1988-2013, tác giả đã đo lường được mức độ tác động của các yếu tố ảnh hưởng đến nhu cầu nhập khẩu cá và tôm của Nhật Bản từ thị trường Việt Nam trong dài hạn và ngắn hạn

\section{Đối với mặt hàng cá}

- Khối lượng đánh bắt cá của Nhật Bản tác động âm lên khối lượng nhập khẩu cá của Nhật Bản từ Việt Nam trong dài hạn $(-4,507472)$.

- Tỷ lệ giữa giá nhập khẩu cá của Nhật Bản từ Việt Nam chia cho giá nhập khẩu cá của các đối thủ cạnh tranh của Việt Nam trên thị trường Nhật Bản có tác động âm lên khối lượng nhập khẩu cá của Nhật Bản từ Việt Nam cả trong dài hạn $(-4,233298)$ và ngắn hạn $(-0,694955)$.

- Tỷ giá hối đoái thực giữa JPY/VNĐ tác động dương lên khối lượng nhập khẩu cá của Nhật Bản từ Việt Nam trong dài hạn $(0,808223)$.

- Khoảng $9,1 \%$ sai biệt giữa giá trị thực tế và giá trị dài hạn của khối lượng nhập khẩu cá của Nhật Bản từ Việt Nam được loại trừ sau mỗi năm.

\section{Trang 126}




\section{Đối với mặt hàng tôm}

- Khối lượng nuôi tôm của Nhật Bản tác động âm lên khối lượng nhập khẩu tôm của Nhật Bản từ Việt Nam trong dài hạn $(-0,905725)$ và ngắn hạn $(-1,646773)$.

- Tỷ giá hối đoái thực giữa JPY/VNĐ tác động dương lên khối lượng nhập khẩu tôm của Nhật Bản từ Việt Nam trong dài hạn $(0,141197)$.

\section{TÀI LIỆU THAM KHẢO}

[1]. Arize, A. C. and Afifi, R. 1987, An Econometrics Examination of Import Demand Function in Thirty Developing Countries, Journal of Post Keynesian, Economics, vol. 9, no. 4, pp. 601-616.

[2]. Arize, A. C. and Walker, J. 1992, A Reexamination of Japan's Aggregate ImportDemand Function: An Application of the Engle and Granger Two-Step Procedure, International Economic Journal, vol. 6, no. 2, pp. 41-55.

[3]. Bond, M. 1985, Export Demand and Supply for Groups of Non-Oil Developing Countries, IMF Staff Paper, vol. 32, pp. 56-77.

[4]. Goldstein, M. and Khan, M. S. 1978, The Supply and Demand for Exports: A Simultaneous Approach, Review of Economics and Statistics, vol. 60, no. 2, pp. 275-286.

[5]. Goldstein, M. and Khan, M. S. 1985, Income and Price Effects in Foreign Trade, in R. W. Jones and P. B. Kenen (eds.), Handbook of International Economics, volume 2: International Monetary Economics and Finance,
- Hiệp định đối tác thương mại Việt Nam Nhật Bản tác động âm lên khối lượng nhập khẩu tôm của Nhật Bản từ Việt Nam trong dài hạn $(-0,352503)$.

- Khoảng 66\% sai biệt giữa giá trị thực tế và giá trị dài hạn của khối lượng nhập khẩu tôm của Nhật Bản từ Việt Nam được loại trừ sau mỗi năm.

Elsevier ScienceB.V., Amsterdam, pp. 1041-1105.

[6]. Gunawardana, P. J. and Karn, P. Ch. 1998, Supply of and Demand for Australia's Pharmaceutical Exports, Working Paper No. 7/98, Department of Applied Economics,Victoria University, Melbourne, Australia.

[7]. Gunawardana, P. J. and Vojvodic, M. 2002, Exchange Rate Volatility and Export Supply Response: Australia's Agricultural, Mineral, and Manufacturing Sectors, Paper presented in the 31st Australian Conference of Economists, Adelaide.

[8]. Gunawardana, P. J., Kidane, H. and Kulendran, N. 1995, Export Supply Response of the Australian Citrus Industry, Australian Journal of Agricultural Economics, vol. 39, no. 3, pp. 247-262.

[9]. Nguyễn Trọng Hoài, Phùng Thanh Bình, Nguyễn Khánh Duy, 2009, Dụ báo và phân tích dũ liệu trong kinh tế và tài chính, Nhà xuất bản Thống kê.

[10]. Paul R.Krugman, Maurice Obstfeld, Marc Melitz (2011), International Economics theory and policy, Addison Wesley. 
[11]. Richard Baldwin, Charles Wyplosz (2012),The Economics of European Integration, McGraw Hill Companies.

[12]. Tổng cục thống kê (2004), Số liệu thống kê Việt Nam thế kỷ XX, Nhà xuất bản thống kê.

[13]. Tổng cục thống kê (2006), Niêm giám thống kê năm 2005, Nhà xuất bản thống kê.

[14]. Tổng cục thống kê (2011), Niêm giám thống kê năm 2010, Nhà xuất bản thống kê.
[15]. Tổng cục thống kê (2014), Niêm giám thống kê năm 2013, Nhà xuất bản thống kê.

[16]. Các website:

- Tổng cục thống kê Việt Nam: www.gso.gov.vn

- Hải quan Nhật Bản: www.customs.gov.jp

- Bộ Nông nghiệp, lâm nghiệp và thủy sản Nhật Bản: www.maff.go.jp

- Ngân hàng thế giới: www.data.worldbank.org 